\title{
REPENSANDO A RESISTÊNCIA INDÍGENA: REFLEXÕES SOBRE A TESE DO MARCO TEMPORAL A PARTIR DO CASO DA TERRA INDÍGENA DE PALMAS/PR
}

\author{
Ricardo Silveira Castro*
}

\section{Resumo}

O presente estudo retomará a discussão a respeito da tese jurídica do marco temporal a partir de um elemento ainda pouco explorado na seara do Direito: a confrontação dos requisitos jurídicos construídos pelo Supremo Tribunal Federal no julgamento do caso Raposa Serra do Sol - em especial a interpretação do quesito da "resistência indígena" necessário para caracterizar o "esbulho remitente" indutor da presunção de que a terra indígena em questão é "tradicionalmente ocupada" - com o valor constitucional do respeito à pluralidade cultural.

Palavras-chave: Direitos indígenas; Constituição Federal de 1988; Democracia; Política

\section{RETHINKING INDIGENOUS RESISTANCE: REFLECTIONS ON THE TIME FRAME THESIS FROM THE CASE OF THE INDIGENOUS LAND OF PALMAS/PR}

\begin{abstract}
:
This study will resume the discussion about the legal thesis of the time frame from an element still little explored in the field of Law: the confrontation of the legal requirements constructed by the Federal Supreme Court in the judgment of the Raposa Serra do Sol case - in particular the interpretation of the question of "indigenous resistance" necessary to characterize the "remitting dispossession" inducing the presumption that the indigenous land in question is "traditionally occupied" - with the constitutional value of respect for cultural plurality.
\end{abstract}

Keywords: indigenous rights; Federal Constitution of 1988; democracy; policy

\section{Introdução}

Importa destacar que as noções abstratas de direitos humanos - independentemente do fundamento assumido pela base teórica - têm impactado negativamente o processo de compreensão dos avanços e retrocessos que o tempo presente contém. Isso porque acabam por surtir um efeito de concebê-los como algo em sua essência alheio à ação humana - e deste forma - desconexo com as dinâmicas sociais. Desse modo,

a partir deste efeito, invertem-se os elementos da equação dos direitos humanos. Inversão usual, típica de teorias abstratas como as teorias liberais, universalistas e

* Doutorando e Mestre em Direito pela Universidade Federal do Rio Grande do Sul. Professor do Curso de Direito das Faculdades Integradas de Taquara (FACCAT). Advogado. E-mail: silveiraricardocastro@gmail.com. 
normativas dos direitos humanos, tal inversão consiste em apresentar o produto como se fosse o próprio fundamento, de tal forma que as normas ou direitos já reconhecidos institucionalmente passem a constituir, em si, os direitos humanos. A par da evidente importância e do significado de conquista que deve ser atribuído ao reconhecimento institucional dos direitos humanos em nível legal, constitucional ou internacional - que assim comumente assumem a gramática de direitos fundamentais, como é possível verificar Perez Luño (2003) e Sánchez Rubio (2014) - ressalte-se que é preciso se atentar para ao menos três consequências ora não enfrentadas, ora ignoradas, ora omitidas pelas teorias abstratas dos direitos humanos, que poderíamos chamar de: 1) efeito encantatório ou ilusório; 2) o efeito imobilizante; 3 ) efeito de ordem. (...) por efeito ilusório podemos entender a situação usual da distância entre direitos previstos e direitos efetivados, de tal forma que a simples previsão legal de um direito passe a servir de substituto, verdadeira ilusão, da sua real efetivação. Desse modo, a ilusão gera também um efeito imobilizante, na medida em que produz, ideologicamente, uma sensação de satisfação, reforçada por um discurso de ordem e justiça social. Assim, através de uma intensa e cotidiana afirmação daquela ilusão imobilizante pelo aparato estatal e social hegemônico, é produzido, finalmente, o efeito de ordem, que reduz a justiça social aos estritos termos e limites do ordenamento jurídico, de tal modo que os direitos humanos passam a ser identificados, limitados e contidos naquele rol de direitos positivados (ESCRIVÃO FILHO; SOUSA JÚNIOR; p.25-26)

A Constituição de 1988 representa um marco jurídico muito importante na luta pela defesa dos direitos das populações indígenas que se encontram inseridas no território do Estado brasileiro. Na ocasião da Assembleia Constituinte (1987-1988),

foi bastante intensa a participação de indigenistas, missionários, antropólogos e advogados não só nas audiências públicas e subcomissões, mas também no debate diário com os parlamentares, informando e apresentando sugestões. Mas o fato inédito e de maior repercussão na rotina parlamentar foi a presença constante de uma massa de indígenas que, pintados e com seus adornos de pena, percorriam os corredores, lotavam os auditórios, entravam e saiam dos gabinetes. Não eram agressivos nem manipuladores, não eram manifestantes que protestavam nem lobistas. Eram pessoas comuns, apenas diferentes, todos confiantes no processo parlamentar, sinceramente preocupados com a defesa de suas comunidades, seus modos de vida e valores diferenciados. Era como se o Congresso estivesse convocado dentro de uma aldeia indígena! Uma presença assim colorida e vistosa tornava evidente aos constituintes e aos funcionários das duas câmaras legislativas o que a sua experiência urbana havia camuflado, a diversidade cultural e linguística do País, a pujança e vivacidade atual de suas populações autóctones (OLIVEIRA, 2016, p.201-202).

Elaborado no contexto da transição política da década de 1980, o texto constitucional foi impactado pelos debates travados em diferentes áreas do conhecimento - sobretudo da História e da Antropologia - ao tratar dos "direitos dos índios". A previsão desses direitos não representou propriamente uma novidade, já que

o princípio dos direitos indígenas às suas terras, embora sistematicamente desrespeitado, está na lei desde pelo menos a Carta Régia de 30 de julho de 1609. O Alvará de $1^{\circ}$ de abril de 1680 afirma que os índios são 'primários e naturais senhores' de suas terras, e que nenhum outro título, nem sequer a concessão de 
sesmarias, poderá valer nas terras indígenas. É verdade que as terras interessavam, na Colônia, muito menos que o trabalho indígena. Mas até quando se inverte o foco desse interesse, em meados do século XIX, e, menos do que escravos, se querem títulos sobre terras, ainda assim se respeita o princípio. Para burlá-lo, inaugura-se um expediente utilizado até hoje: nega-se sua identidade aos índios. E, se não há índios, tampouco há direitos. Quanto ao direito constitucional, desde 1934, é respeitada a posse indígena inalienável das suas terras. Diga-se em sua honra, foi na bancada amazonense que teve origem a emenda que consagrou esses direitos em 1934. Todas as Constituições subsequentes mantiveram e desenvolveram esses direitos, e a Constituição de 1988 deu-lhes sua expressão mais detalhada (CUNHA, 2012, p.127)

Rompendo com o paradigma jurídico assimilacionista, o texto constitucional de 1988 reconheceu aos índios proteção as suas organizações sociais, costumes, línguas, crenças e tradições - além do que, constou expressamente na Constituição Cidadã o dever do Estado de demarcar as terras tradicionalmente ocupadas pelas populações indígenas ${ }^{2}$. A disputa pela efetividade da literalidade constitucional ensejou diversas batalhas - tanto no campo político quanto no campo jurídico. A principal batalha jurídica (de repercussão nacional) foi travada no julgamento do caso paradigmático da demarcação da terra indígena Raposa Serra do Sol (em Roraima), ocasião em que emergiu a baliza atualmente vigente para casos de demarcação conflituosa de terras indígenas: a tese do marco temporal.

O presente estudo retomará a discussão a respeito da tese jurídica do marco temporal a partir de um elemento ainda pouco explorado na seara do Direito: a confrontação dos

2 Artigo 231 da Constituição Federal de 1988. São reconhecidos aos índios sua organização social, costumes, línguas, crenças e tradições, e os direitos originários sobre as terras que tradicionalmente ocupam, competindo à União demarcá-las, proteger e fazer respeitar todos os seus bens.

$\S 1^{\circ}$ São terras tradicionalmente ocupadas pelos índios as por eles habitadas em caráter permanente, as utilizadas para suas atividades produtivas, as imprescindíveis à preservação dos recursos ambientais necessários a seu bem-estar e as necessárias a sua reprodução física e cultural, segundo seus usos, costumes e tradições.

$\S 2^{\circ}$ As terras tradicionalmente ocupadas pelos índios destinam-se a sua posse permanente, cabendo-lhes o usufruto exclusivo das riquezas do solo, dos rios e dos lagos nelas existentes.

$\S 3^{\circ} \mathrm{O}$ aproveitamento dos recursos hídricos, incluídos os potenciais energéticos, a pesquisa e a lavra das riquezas minerais em terras indígenas só podem ser efetivados com autorização do Congresso Nacional, ouvidas as comunidades afetadas, ficando-lhes assegurada participação nos resultados da lavra, na forma da lei.

$\S 4^{\circ}$ As terras de que trata este artigo são inalienáveis e indisponíveis, e os direitos sobre elas, imprescritíveis.

$\S 5^{\circ}$ É vedada a remoção dos grupos indígenas de suas terras, salvo, "ad referendum" do Congresso Nacional, em caso de catástrofe ou epidemia que ponha em risco sua população, ou no interesse da soberania do País, após deliberação do Congresso Nacional, garantido, em qualquer hipótese, o retorno imediato logo que cesse o risco.

$\S 6^{\circ}$ São nulos e extintos, não produzindo efeitos jurídicos, os atos que tenham por objeto a ocupação, o domínio e a posse das terras a que se refere este artigo, ou a exploração das riquezas naturais do solo, dos rios e dos lagos nelas existentes, ressalvado relevante interesse público da União, segundo o que dispuser lei complementar, não gerando a nulidade e a extinção direito a indenização ou a ações contra a União, salvo, na forma da lei, quanto às benfeitorias derivadas da ocupação de boa fé.

$\S 7^{\circ}$ Não se aplica às terras indígenas o disposto no art. $174, \S 3^{\circ}$ e $\S 4^{\circ}$. 
requisitos jurídicos construídos pelo Supremo Tribunal Federal no julgamento do caso Raposa Serra do Sol - em especial a interpretação do quesito da "resistência indígena" necessário para caracterizar o "esbulho remitente" indutor da presunção de que a terra indígena em questão é "tradicionalmente ocupada" - com o valor constitucional do respeito à pluralidade cultural. Nesse sentido, reconstituir-se-á o debate pretoriano a respeito da terra indígena de Palmas/PR para evidenciar o impacto que essa interpretação restritiva da noção de "resistência indígena" pode apresentar na violação dos direitos constitucionais fundamentais das populações indígenas.

\section{Qual "resistência"? Evidenciando o resquício essencialista da tese do marco temporal}

Em março de 2009, o plenário do Supremo Tribunal Federal - ao concluir o julgamento da Petição n.3.388, publicamente conhecida como o "caso Raposa Serra do Sol" firmou a tese do marco temporal, que serve de norte para a jurisprudência nacional em matéria de demarcação de terras indígenas. Nesse caso em particular, houve questionamento do Estado de Roraima e de municípios afetados pela demarcação contínua projetada na Portaria n.543/2005, do Ministério da Justiça, posteriormente homologada pelo Presidente da República, Luís Inácio Lula da Silva. A análise do caso concreto revela que

A discussão da demarcação da Terra Raposa Serra do Sol se arrastou por mais de trinta anos. Em 1993, a FUNAI solicitou ao Ministério da Justiça o reconhecimento de uma área equivalente a 1,67 milhões de hectares. Na época, mais de vinte contestações administrativas foram apresentadas, as quais foram negadas pelo Ministro da Justiça, Nelson Jobim, no ano de 1996. Em 1998, Renan Calheiros, então Chefe do Ministério da Justiça, assinou portaria declarando a região como sendo de posse permanente dos povos indígenas e em área contínua. Em 2002, o Estado de Roraima impetrou mandado de segurança contra referida Portaria. O recurso foi negado e seguiu-se com o andamento do processo demarcatório. Houve uma série de outros fatos, até que em 2005, o Ministro Márcio Thomaz Bastos assinou a Portaria 534 e o Presidente Luiz Inácio Lula da Silva assinou decreto homologando a demarcação da Terra Indígena Raposa Serra do Sol, determinando a posse das terras aos grupos indígenas Ingarikó, Makuxi, Patamona, Taurepang e Wapixana. Em 2005, os Senadores Augusto Affonso Botelho Neto (na época filiado ao PDT) e Francisco Mozarildo de Melo Cavalcanti (PTB) ingressaram com ação popular contra a União na qual requereram liminarmente a suspensão e, definitivamente, a anulação da Portaria 534/2005 (STARCK; BRAGATO; 2020, p.249-250). 
Embora tenha negado os pedidos formulados pelos entes federados subnacionais - em clara tomada de posição a favor da política de proteção das terras indígenas - a mais alta Corte de justiça do país fixou entendimento restritivo quanto à comprovação da ocupação tradicional desses territórios. No mencionado julgamento,

foi o Ministro Carlos Alberto Menezes Direito quem apresentou as dezenove condicionantes e iniciou seu voto dizendo que não há índio sem terra e destacando a essencialidade da terra para a garantia de direitos desses povos.11Ainda que, de nada adianta reconhecer-lhes os direitos sem assegurar-Ihes as terras, identificando-as e demarcando-as. Seguiu fazendo uma análise da Teoria do Fato Indígena, a qual deve ser condicionada ao interesse público. Referiu que os interesses contrários às demarcações precisam ser ouvidos e que a definição da terra a ser demarcada não pode ser um poder absoluto dos índios tendo em vista que o interesse público está no mesmo patamar que o direito dos povos indígenas. Entendeu que é imprescindível definir prerrogativas e restrições para que seja definido o que é terra indígena, momento do Voto em que começa a surgir a ideia da necessidade de fixação de condicionantes (STARCK; BRAGATO; 2020, p.253)

Em termos sintéticos, a tese do marco temporal reconhece que a Constituição Federal de 1988 trabalhou com data "certa" (5 de outubro de 1988, a data da sua promulgação) como insubstituível referencial para o dado da ocupação de um determinado espaço geográfico ser legitimamente protegida como terra indígena. Em outras palavras, tal precedente jurisprudencial estabeleceu como pré-requisito indispensável para a proteção jurídica de determinada terra indígena a comprovação da ocupação tradicional desse perímetro territorial na data da promulgação do texto constitucional vigente. Nesse sentido, tornou-se incumbência das comunidades indígenas interessadas em demarcar seus respectivos territórios comprovar referida ocupação tradicional desde - pelo menos - 5 de outubro de 1988.

O tema envolvendo a demarcação das terras indígenas voltou à pauta do Supremo Tribunal Federal por meio do Recurso Extraordinário n.1.017.365 em fevereiro de 2019, ocasião em que - no momento da avaliação da admissibilidade do recurso - ficou assentado que "é dotada de repercussão geral a questão constitucional referente à definição do estatuto jurídico-constitucional das relações de posse das áreas de tradicional ocupação indígena à luz das regras dispostas no art. 231 do texto constitucional” (BRASIL, 2019). Nesse processo, o Ministério Público Federal defendeu a insustentabilidade da tese do marco temporal. Até a conclusão do presente texto, o julgamento do mencionado Recurso Extraordinário - que tem o potencial de afastar a aplicação da tese do marco temporal - estava suspenso em razão do pedido de vistas do Ministro Alexandre de Moraes. 
No campo do Direito, esse tema mereceu atenção de vários trabalhos que enfocaram a atuação legislativa do Poder Judiciário (por meio do seu órgão de instância máxima, o Supremo Tribunal Federal). A discussão travada na literatura jurídica se limitou a avaliar a crítica segundo a qual a tese do marco temporal fixada no julgamento do caso Raposa Serra do Sol representou uma violação do texto constitucional - na medida em que houve limitação de um direito fundamental estabelecido pelo poder constituinte por uma instância judicial (poder constituído) desprovido de legitimidade para tanto. Em que pese essa questão ser de extrema relevância - sobretudo para os estudos que buscam compreender o constitucionalismo democrático do século XXI (vide as experiências constitucionais do Equador e da Bolívia, por exemplo) - nosso foco no presente trabalho será outro.

Ao estabelecer a tese do marco temporal, o Supremo Tribunal Federal reconheceu uma única exceção: nas situações em que fossem comprovado o "esbulho renitente por não-índios" dispensariam a prova da ocupação tradicional pelas populações indígenas. Em termos jurídicos, "esbulho" é a expressão que traduz a perda da posse de um determinado bem, isto é, trata-se de uma agressão que provoca a perda do controle e da atuação material sobre um determinado bem (ROSENVALD; FARIAS, 2013, p.208).

Portanto, de acordo com a Suprema Corte brasileira, no caso de haver situação de esbulho que persiste desde a promulgação do texto constitucional vigente, seria possível flexibilizar a tese do marco temporal e, nesses casos excepcionais, promover a demarcação de terra indígena mesmo sem comprovação da posse (em outubro de 1988) da área geográfica reivindicada. $\mathrm{O}$ que se pretende pôr em evidência nessa ocasião é a fragilidade da argumentação judicial no momento de delimitar as alternativas capazes de configurar o referido "esbulho renitente", sobretudo porque o critério de atração dessa resposta excepcional apresenta concepções já bastante questionadas nos campos da História e da Antropologia.

Em apertada síntese, é possível afirmar que o Supremo Tribunal Federal reconhece a existência de "esbulho renitente" nas situações em que é constatada a resistência persistente da população indígena contra o esbulho promovido por não índios (DUPRAT, 2018, p.44). O problema que se apresenta é: do que estamos falando quando dizemos "resistência" indígena? É nessa direção que pretendemos caminhar para estabelecer um diálogo entre estudos contemporâneos críticos da História e da Antropologia com a prática jurisprudencial que permanece reproduzindo entendimentos fortemente marcados por um discurso que 
estigmatiza comportamentos que não estão em conformidade com o imaginário do "índio puro", que está estreitamente vinculado à imagem do guerreiro intransigível e insuscetível ao diálogo e às adaptações inerentes ao contato com a sociedade envolvente.

Nesse sentido, a contribuição que a História e a Antropologia podem oferecer para análise em questão vincula-se à superação da concepção simplista segundo a qual a "resistência" exclui a "adaptação" - como se um e outro fossem conceitos estanques, delimitados em contraposição recíproca. Para retornar ao debate proposto: será que realizar acordos e ceder a eventuais perdas em determinado contexto territorial (mediante garantia de ganhos em outros, que assegurem a estabilidade e a coesão do grupo) importa na desqualificação desse comportamento enquanto resistência? Para embasar essa reflexão, utilizaremos o referencial teórico desses campos do saber social que têm apresentado avanços significativos na reformulação do binômio "resistência" e "aculturação".

As últimas décadas do século XX foram marcadas, no campo da História e da Antropologia, por trabalhos acadêmicos que propuseram um novo olhar epistemológico para a ação indígena - até então subestimada por paradigmas estigmatizantes.

Conforme destacado por Maria Regina Celestino de Almeida (2017, p.20)

Predominantes em nossa historiografia e continuamente alimentadas pela mídia e pelas narrativas históricas em escolas, colégios e universidades, essas ideias foram facilmente incorporadas no imaginário da população brasileira, com imensos prejuízos para todos, mas principalmente para os índios. Duplamente violentados, como afirmou Carneiro da Cunha (1992), pois além de terem enfrentado as trágicas consequências dos processos históricos vivenciados, sofreram e ainda sofrem os efeitos da história disciplina, na qual figuram em papéis secundários e depreciativos, entre as posições de vítimas passivas, bons selvagens ou bárbaros sanguinários. Historicídio, nas palavras de Hill (1996), que contribuiu para reforçar em nossa sociedade ideias preconceituosas e estereotipadas sobre eles.

A crítica a essa visão epistemológica emerge na medida em que novas perspectivas marcadas pela interdisciplinaridade ganham espaço nas ciências sociais no contexto latinoamericano. Nesse sentido, Guillaume Boccara (2005, p.30) explica que

Por su parte, los estudios latinoamericanistas sobre fenómenos sociales tan fundamentales como la guerra, el estado, el parentesco, el shamanismo, la historicidad de los pueblos no-occidentales o las conceptualizaciones indígenas del medio ambiente han tendido a alimentar la reflexión antropológica más allá del área cultural considerada. Con respecto a la antropología histórica, la fecundidad de una aproximación que combina los métodos y perspectivas de la historia y de la etnología ha permitido, por un lado, restituir a las sociedades amerindias un poco de su espesor sociohistórico y, por otro, ha conducido a la elaboración de nuevos objetos y problemas de estudio. El uso de papeles de archivos que no habían sido 
explotados hasta hace poco, así como la relectura de crónicas y relaciones de la época colonial desde una óptica y un cuestionamiento propiamente antropológicos ha contribuido a hacer emerger progresivamente nuevas facetas del llamado Nuevo Mundo: las facetas negra, mestiza, indígena, marrana, etc

Nesse sentido, foi-se demonstrando que "aculturação" não pode ser traduzida como sinônimo de mera conversão e, igualmente, tampouco foi percebida e interpretada pelos mesmos agentes sociais como abandono das tradições chamadas de ancestrais (BOCCARA, 2005, p.24). Em estudo que influenciaria de forma significante as abordagens americanistas, Nathan Wachtel esclarece que resistência e revolta não são sinônimos de vontade de perpetuar uma tradição estática e congelada no tempo - ou seja - a resistência dos povos nativos não remete a uma operação meramente conservadora de preservação ou de retorno às tradições e aos modos de organização social pré-hispânicos (BOCCARA, 2005, p.24).

De igual modo, figura como central nessa discussão a refutação de concepções idealizadoras, construídas com base na tradição essencialista e preconceituosa das sociedades nativas. Nesse compasso, criações, reformulações e reinterpretações de tradições nativas realizadas por populações indígenas em contato com a sociedade envolvente não devem ser tratadas como contaminações que conduzem ao inevitável desaparecimento do ser social indígena, ou de uma suposta pureza cultural original (BOCCARA, 2005, p.29).

A relevância desse aspecto é tamanha que

\begin{abstract}
Las aproximaciones en términos de esencia cultural se encuentran invalidadas por Wachtel quien aprovecha la oportunidad para poner en tela de juicio el corte articificial e ideológicamente nefasto entre sociedades primitivas ("las otras"), por un lado, y sociedades históricas ("las nuestras"), por el otro (Wachtel 1974: 199). Así es como, al criticar radicalmente la dicotomía entre "sociedades frías" y "sociedades calientes", Wachtel abre un camino que permite revisar otra serie de dudosas oposiciones tales como pureza originaria versus mestizaje, estructura versus historia, etc. (BOCCARA, 2005, p.29).
\end{abstract}

No Brasil, essa temática emergiu no horizonte político na ocasião do processo constituinte de 1987, durante a identificação das etnias indígenas dentre do território nacional. Aliás, foi somente em razão de demandas quanto à terra que povos indígenas de algumas regiões do país - como do Nordeste, por exemplo - foram colocados como objeto de atenção para antropólogos vinculados às universidades locais. Tomando o caso dos índios do Nordeste, é notável o descrédito conferido à unidade e à consistência desse grupo cultural, estigmatizado pelo processo de aculturação. 
A demonstração empírica dessa realidade é evidenciada por João Pacheco de Oluveira (1998, p.48) ao esclarecer que

\begin{abstract}
Em seu trabalho de classificação das áreas culturais indígenas existentes no país, Eduardo Galvão (1979, 225-226) manifesta dúvidas quanto à última delas — a XI, intitulada "nordeste" - possuir, efetivamente, uma unidade e consistência igual às demais. $\mathrm{O}$ autor destaca desde logo os efeitos da aculturação e o seu diagnóstico sobre as dez etnias dessa área cultural é o seguinte: "A maior parte vive integrada no meio regional, registrando-se considerável mesclagem e perda dos elementos tradicionais, inclusive a língua". Ao mencionar os Pataxó, o autor agrega (sem aspas) o adjetivo "mestiçados". É importante lembrar que o artigo de Galvão - por seu caráter introdutório e classificatório - constitui um dos textos mais consultados não só por estudantes de antropologia, mas também por museólogos, bibliotecários, educadores e comunicadores sociais em geral.
\end{abstract}

No campo jurídico-político a reformulação das noções de "resistência" e de “aculturação" pode servir de subsídio à alteração do paradigma essencialista que segue impondo restrições aos direitos fundamentais reconhecidos pela Constituição Federal de 1988 às populações indígenas - especialmente no que tange aos direitos territoriais. A delimitação de uma espécie de comportamento (enfrentamento direito, isto é, oposição ativa mediante confronto aberto e deflagrado) como única alternativa legítima a configurar a "resistência" suficiente ao reconhecimento de direitos territoriais de comunidades indígenas é uma violência institucional que permanece sendo chancelada pela cúpula do Poder Judiciário brasileiro, em evidente afronta ao postulado constitucional do pluralismo político e cultural (artigo $1^{\circ}$, inciso V da Constituição de 1988). É exatamente nesse particular que a questão da tese do marco temporal impacta a discussão, pois

\footnotetext{
A exigência do marco de 05 de outubro de 1988, como forma de estabelecer aos indígenas o direito de terem consideradas suas terras como tradicionalmente ocupadas, acaba por ignorar as diversas circunstâncias que provocaram a saída de vários grupos indígenas de suas terras. Pois, esses processos aconteceram de várias formas configurando inclusive o chamado esbulho renitente. $\mathrm{O}$ esbulho renitente trouxe diversas formas de retirada dos indígenas de suas terras como, por exemplo, situações em que as comunidades indígenas foram removidas por convencimentos das autoridades governamentais ou pela aproximação com o homem branco. Em muitos casos, foram expulsos no processo de colonização e ocupação dessas terras para a produtividade agropecuária no país (DAN; ASSIS; 2020, p.275)
}

A questão que se coloca é justamente sobre o entendimento do que consiste a resistência indígena, conforme enfatizado por Samuel Barbosa (2018, p.132):

Mas o que é resistência indígena? Aqui entra o trabalho de pesquisa para mostrar os diferentes tipos de resistência, que variam para cada povo. Não é apenas a 
resistência física e violenta. Índios que permanecem próximos à área, realizando pequenos furtos, coleta e pesca nas áreas esbulhadas podem configurar uma forma de resistência. Índios que se tornam empregados de fazendeiros para permanecerem na terra e realizar seus ritos, também é uma forma de resistência. Há uma miríade de formas de resistência quase invisíveis, "the weapons of the weak", como chama James Scott. O conceito de esbulho de terras indígenas não pode ser uma construção monológica da dogmática do direito civil. Retração voluntária (desistência de resistir ao esbulho) ou o abandono da terra não podem ser presumidos nem constatados exclusivamente segundo critérios do direito civil.

Com o fim de demonstrar os efeitos práticos desse debate teórico, analisaremos o percurso do recente conflito judicial envolvendo a terra indígena da Comunidade Kaingang de Palmas (localizada no Paraná).

\section{A terra indígena de Palmas/PR: um caso de resistência}

O processo administrativo de demarcação da terra indígena de Palmas - localizada na divisa dos estados de Santa Cataria e Paraná - embora iniciado (com a realização da identificação e revisão do território pelos parâmetros jurídicos estabelecidos pós-1988) em 2000, restou concluído somente em 2007, com a homologação da portaria do Ministério da Justiça pelo Presidente da República. Em 2012, entretanto, uma ação judicial protocolada perante a $1^{\text {a }}$ Vara Federal de Pato Branco (PR) reabriu a discussão a respeito dos limites do território indígena de Palmas. A autora da ação judicial sustentou ser proprietária de uma área de terras rurais (mais precisamente da Fazenda Santa Maria, em Palmas/PR) indevidamente apontada pela Fundação Nacional do Índio (FUNAI) como de ocupação, domínio e posse tradicionais de grupos indígenas kaingang (BRASIL, 2013).

O processo judicial conduzida pelo juízo federal de Pato Branco (PR) chama atenção por representar um exemplo claro de incidência do debate a respeito dos limites da tese do marco temporal, elencado como critério insubstituível para obtenção da proteção constitucional de terras indígenas. A autora da ação embasou seu pedido justamente nesse argumento jurídico, afirmando que sua propriedade - isto é, a Fazenda Santa Maria localizada no município de Palmas/PR - não estava sendo ocupada pelos índios no dia da promulgação da Constituição de 1988 e, por essa razão, postulou a declaração da nulidade do ato administrativo demarcatório da terra indígena de Palmas (BRASIL, 2013). 
Os documentos juntados aos autos do processo judicial atestaram que o laudo antropológico (levado a efeito por analista do Ministério Público Federal) fixou os limites fronteiriços da terra indígena com base em estudos técnicos de cunho histórico, geográfico e cultural, realizados conjuntamente com consultas prévias aos proprietários rurais de áreas limítrofes à terra indígena em demarcação. Não obstante essa realidade, comprovou-se que na data da promulgação do texto constitucional vigente o território objeto da discussão judicial não estava na posse da comunidade indígena Kaingang.

Apesar de todos os subsídios documentais, fotográficos e cartográficos ratificando a existência de reivindicação constante dos indígenas Kaingang desde 1961 pela inclusão do território da fazenda Santa Maria ao perímetro de suas terras - uma vez que tal área é imprescindível à preservação dos recursos ambientais necessários ao bem estar dos indígenas e necessária à sua reprodução física e cultural, segundo seus usos, costumes e tradições - a ação foi julgada procedente para declarar a nulidade do procedimento administrativo que culminou no reconhecimento do imóvel rural em comento (fazenda Santa Maria) como de posse tradicional indígena (BRASIL, 2013)..

Em junho de 2015, a $4^{\text {a }}$ Turma do Tribunal Regional Federal da $4^{\mathrm{a}}$ Região analisou os recursos interpostos contra a decisão do Juízo Federal de Pato Branco, julgando improcedente os pedidos com base na tese do marco temporal. Em conformidade com o entendimento do colegiado, como na data da promulgação da Constituição Federal de 1988 não havia ocupação da área reivindicada pela comunidade kaingang de Palmas nem prova de resistência ativa dos índios contra eventual esbulho de proprietários particulares ou ilegalidades cometidas pelos Poderes Públicos, não haveria argumentação plausível capaz de embasar a reforma da decisão proferida pelo juiz singular (BRASIL, 2015).

Como se pode perceber, a compreensão de "resistência" legítima a atrair a incidência da proteção constitucional de terras tradicionais está vinculada à perspectiva do purismo indígena, que pressupõe a existência de um "modo de ser índio". Mesmo diante de provas documentais evidenciando a disputa do território da fazenda Santa Maria pelos meios institucionais (administrativos, sobretudo), as alegações da Fundação Nacional do Índio (FUNAI) foram completamente desconsideradas.

Nesse ponto em particular, chama atenção o fato de que a compreensão dos direitos dos povos indígenas chancelada pelo Poder Judiciário não permitiu o enfoque intercultural. A complexidade dos direitos humanos reside em que eles podem ser concebidos, quer como 
forma de localismo globalizado, quer como forma de cosmopolitismo, ou, por outras palavras, quer como globalização hegemônica, quer como globalização contra hegemônica (SANTOS, 1997, p.18). Diante do desafio de refletir sobre uma aproximação de diferentes perspectivas culturais sobre um valor (propriedade), emerge como instrumento útil a noção de hermenêutica diatópica. Conforme leciona Boaventura de Souza Santos (1997, p.23)

No caso de um diálogo intercultural, a troca não é apenas entre diferentes saberes, mas também entre diferentes culturas, ou seja, entre universos de sentidos diferentes e, em grande medida, incomensuráveis. Tais universos de sentido consistem em constelações de topoi fortes. Os topoi são os lugares comuns retóricos mais abrangentes de determinada cultura. Funcionam como premissas de argumentação que, por não se discutirem, dada a sua evidência, tornam possível a produção e a troca de argumentos. Topoi fortes tornam-se altamente vulneráveis e problemáticos quando usados numa cultura diferente. $\mathrm{O}$ melhor que lhes pode acontecer é serem desprovidos de premissas de argumentação a meros argumentos. Compreender determinada cultura a partir do topoi de outra cultura pode revelar-se muito difícil, se não mesmo impossível. Partindo do pressuposto de que tal não pe impossível, proponho a seguir uma hermenêutica diatópica, um procedimento hermenêutico que julgo adequado para nos guiar nas dificuldades de enfrentar, ainda que não necessariamente para as superar. $\mathrm{Na}$ área dos direitos humanos e da dignidade humana, a mobilização de apoio social para as possibilidades e exigências emancipatórias que eles contêm só será concretizável na medida em que tais possibilidades e exigências tiverem sido apropriadas e absorvidas pelo contexto cultural local. Apropriação e absorção, neste sentido, não podem ser obtidas através da canibalização cultural. Requerem um diálogo intercultural e uma hermenêutica diatópica.

A contradição existente entre os princípios constitucionais estabelecidos na Constituição de 1988 e as decisões proferidas pelas instâncias da justiça federal da $4^{\text {a }}$ Região - quais sejam, o juízo federal de Pato Branco/PR e a $4^{\mathrm{a}}$ Turma do Tribunal Regional Federal instaram ainda o ajuizamento de recursos ao Superior Tribunal de Justiça (Recurso Especial) e ao Supremo Tribunal Federal (Recurso Extraordinário).

Em ambos os tribunais superiores, no entanto, não houve admissão dos mecanismos recursais em razão de formalidades processuais (súmula proibindo reexame das provas juntadas aos autos, por exemplo) - de tal modo que, o mérito da questão envolvendo a anulação parcial do ato de demarcação da terra indígena de Palmas/PR não foi examinado pelas instâncias superiores do Poder Judiciário brasileiro. O trânsito em julgado envolvendo essa questão específica ocorreu em abriu de 2019.

Inconformados com a decisão judicial proferida pelo juízo federal de Pato Branco e mantida por todas as instâncias de revisão, os integrantes da comunidade indígena kaingang de Palmas/PR manejaram ação rescisória, em agosto de 2019, postulando a concessão de medida liminar que impedisse o cumprimento da ordem de desocupação contra eles emitida. 
Surpreendentemente, em setembro de 2019 a Ministra relatora da ação rescisória interposta pela comunidade kaingang deferiu liminar para impedir o despejo iminente, sob o argumento de que a população kaingang não foi efetivamente consultada no processo judicial que tramitou na justiça federal do Paraná, o que violaria o direito à ampla defesa e ao contraditório.

Destaque-se que a media concedida pelo Supremo Tribunal Federal, em 2019, emerge em um contexto político de acumulados retrocessos nas políticas públicas indigenistas. Nesse sentido,

se é verdade que nas três décadas posteriores à aprovação do texto constitucional de 1988 os movimentos sociais indígenas protagonizaram batalhas (políticas e jurídicas) cotidianas para efetivar direitos fundamentais ameaçados por estruturas institucionais excludentes e elitistas, é inegável que o caminho percorrido a partir de janeiro de 2019 tornou-se ainda mais tortuoso. A implementação da agenda neoliberal que logrou êxito nas eleições de outubro de 2018 teve impactos diretos na remodelação do arcabouço jurídico construído no último período de redemocratização, sobretudo no desmonte do "Estado Social" pretendido pela Constituição de 1988 - que em seu artigo $3^{\circ}$ reconhece como objetivo fundamental da República Federativa do Brasil a construção de uma sociedade "livre, justa e solidária".

No fluxo de ruptura com os consensos básicos da modernidade (FARINAS DULCE, 2019), o projeto neoliberal em curso no Brasil ataca imediatamente as bases de solidariedade social e da ordem moral que sustentaram o movimento constituinte de 1987-1988. Diversos movimentos praticados pelo governo empossado em janeiro de 2019 demonstram o seu projeto contrarreformista que tem sido implementado inclusive por meio do "jogo duro constitucional" (LEVITSKY; ZIBLATT, 2018) praticado pelo Presidente da República.

A reforma administrativa proposta nos primeiros meses da nova gestão pretendeu desvincular a Fundação Nacional do Índio (FUNAI) do Ministério da Justiça e submetê-lo ao Ministério da Mulher, da Família e dos Direitos Humanos assim como buscou atribuir ao Ministério da Agricultura, Pecuária e Abastecimento a competência de demarcação das terras indígenas 20 , com a finalidade de obstruir tais processos e direcionar esses assuntos a uma pasta governamental sem afinidade temática imediata e com interesses antagônicos à preservação dos direitos dos povos indígenas - com o impacto direto na associação desses processos a um setor da burocracia estatal carente de conhecimentos técnicos no assunto. A reforma administrativa acabou não prosperando por conta da organização dos povos indígenas que conseguiram bloquear esse evidente regresso no Judiciário, por meio de provocação do Supremo Tribunal Federal (VESOLOSQUZKI KAINGANG; CASTRO, 2020, p.139-140).

Note-se que a suspensão da ordem de despejo está fundamentada na inexistência de participação da comunidade Kaingang de Palmas na ação que resultou na anulação parcial da Portaria do Ministério da Justiça que reconhecia a ocupação tradicional indígena na fazenda Santa Maria. Nenhuma consideração foi registrada a respeito da necessidade de se desconstituir o ideal do "índio puro", que está na base da negação do reconhecimento dos 
direitos da comunidade kaingang de Palmas sobre o território da área rural em disputa com fazendeiros.

É notável a atuação persistente dos kaingang de Palmas em reivindicar e resistir ao esbulho praticado por particulares em suas terras tradicionais. Em praticamente todos os âmbitos jurisdicionais para os quais esse caso foi levado (seja em primeira instância, seja nos tribunais superiores) foi relatado o esforço das lideranças da comunidade em demonstrar que as primeiras demarcações da terra indígena de Palmas - realizadas pela FUNAI ainda nas décadas de 1960 e 1970 - estavam equivocadas por não inserirem o espaço geográfico da fazenda Santa Maria, que representa parte fundamental do território da comunidade indígena - que precisa dele para preservar sua história e tradição fortemente vinculada ao seu significado espiritual.

Importante destacar que na relação entre os Kaingang de Palmas e os proprietários rurais - desde pelo menos o início do século XIX - é possível identificar diferentes formas de interação, que passam pela prática do colaboracionismo até o enfrentamento pela resistência armada - o que pode ser constatado pela subdivisão dos indígenas em "mansos" e "arredios" nos documentos do período (FERNANDES, 1998, p.72). Pretender estabelecer um padrão que se vincule à natureza pura dos kaingang da região é desconsiderar a complexidade que envolve a compreensão das formas de relacionamento entre indígenas e não indígenas complexidade esta expressada na própria ambiguidade de posicionamentos assumidos por distintas lideranças no contato com a sociedade envolvente.

O registro das reuniões administrativas com as lideranças da comunidade, reverberada pela participação da FUNAI nessas instâncias judiciais revela que a estratégia utilizada pelos indígenas Kaingang de Palmas para convencimento da ocupação tradicional nesse caso específico foi o estabelecimento de uma via de diálogo. Por que não reconhecer essa alternativa como uma forma de resistência? Negar por via judicial às comunidades indígenas a capacidade de avaliar as melhores opções de resistir frente aos ataques às suas tradições, costumes e organização é uma forma de preservar o preconceito colonialista de maneira institucional, ao arrepio do que dispõe a Constituição Federal de 1988.

\section{Considerações finais}


A emergência de um novo paradigma jurídico-constitucional a partir de 1988 representou avanço significativo no processo histórico da luta dos povos indígenas por reconhecimento. A conquista no âmbito da dogmática constitucional - isto é, na inclusão de direitos fundamentais nunca antes expressados nos marcos constitucionais brasileiros anteriores - não afastou, no entanto, o discurso essencialista das práticas institucionais do Poder Judiciário, responsável pela efetivação do pacto concluído em 5 de outubro de 1988.

No debate envolvendo a efetividade dos direitos fundamentais das populações indígenas, a Suprema Corte brasileira tem perpetuado o entendimento firmado no caso Raposa Serra do Sol segundo o qual a demarcação de terras indígenas (com a incidência de todo o estatuto protetivo decorrente desse processo) depende da comprovação da posse indígena do território postulado à época da promulgação da Constituição Federal de 1988 ou de resistência da referida comunidade frente ao esbulho renitente de proprietários vizinhos.

O foco do presente trabalho foi justamente evidenciar o equívoco cometido pelo Poder Judiciário brasileiro em persistir numa avaliação essencialista e preconceituosa dos indígenas, que evidencia a incapacidade das estruturas estatais - nesse caso em especial - em promover um diálogo intercultural.

Nesse sentido, a resistência indígena reconhecida como suficiente para atrair a proteção constitucional dos direitos territoriais é aquela vinculada à concepção do "índio puro", intransigente e que busca, mediante violência, manter a qualquer custo suas tradições sem "contaminações". Comportamentos que possam ser associadas a estratégias de colaboração e diálogo, ou seja, de interações não violentas, são percebidos como não legítimos e, portanto, inaptos para gerar a proteção jurídica especial prevista no texto constitucional vigente.

A disputa judicial envolvendo a demarcação da Terra Indígena de Palmas/PR revela os impactos adversos da perpetuação da concepção essencialista que tem o potencial de tornar sem efeito preceitos que integram o núcleo da Constituição Cidadã de 1988. Mesmo diante das provas documentais comprovando que a comunidade Kaingang de Palmas utilizara os mecanismos administrativos de reivindicação disponibilizados pela FUNAI e, que na data de 5 de outubro de 1988 seguia postulando perante as autoridades locais a retificação da extensão de suas terras tradicionais, as instâncias judiciais envolvidas negaram a incidência da proteção constitucional no caso em concreto. 
Nesse contexto, a prevalência do argumento segundo o qual não houve resistência da comunidade indígena de Palmas/PR representa uma restrição injustificável do conceito de "resistência" - razão pela qual uma interlocução com outras áreas do saber se faz necessária. A problematização do binômio "resistência" e "aculturação" (que nos remete à distinção entre “índios puros" e "índios misturados”) precisa ser enfrentada pelos juristas que pretendem dar efetividade aos dispositivos constitucionais envolvendo direitos fundamentais indígenas; tanto a História quanto a Antropologia têm muito a contribuir com essas reflexões.

No detalhe, percebe-se que a ordem (proferida pelo Supremo Tribunal Federal) de suspensão da desapropriação que afastaria a comunidade Kaingang de Palmas/PR de suas terras tradicionalmente ocupadas trouxe como fundamente a ausência da participação dos indígenas no processo judicial que questionou a demarcação de suas terras. A oportunidade de arguir a sua defesa, na demonstração dos esforços movidos para preservação do seu modo de ser e viver naquela localidade, pode vir a ser um primeiro passo importante na construção do - até então ausente - diálogo intercultural que deve nortear a discussão. Se isso efetivamente vai acontecer, só a dinâmica de interação entre as instituições estatais e os movimentos sociais organizados é que demonstrará.

\section{Referências bibliográficas}

ALMEIDA, Maria Regina Celestino de. "A atuação dos indígenas na História do Brasil: revisões historiográficas”, in: Revista Brasileira de História, São Paulo, vol.37, n.75, 2017. P.17-38

BARBOSA, Samuel. "Usos da história na definição dos direitos territoriais indígenas no Brasil”, p.125-137. In: CUNHA, Manuela Carneiro da; BARBOSA, Samuel (Orgs.). Direitos dos povos indígenas em disputa. São Paulo: Editora UNESP, 2018.

BOCCARA, Guillaume. "Génesis y estrutura de los complexos fronterizos euro-indígenas. Repensando los márgenes americanos a partir (y más allá) de la obra de Nathan Wachtel", Memoria Americana 13- Año 2005, p. 21-52.

BRASIL. JUÍZO FEDERAL DA $1^{\text {a }}$ VARA FEDERAL DE PATO BRANCO DO ESTADO DO PARANÁ. Ação ordinária n. 5001335-13.2012.4.04.7012. Juiz Federal Rafael Webber. Julgado em 14 de Junho de 2013. Disponibilizado no diário eletrônico em 17/06/2013. Disponível em: https://www.jfpr.jus.br/. 
QUARTA TURMA DO TRIBUNAL REGIONAL FEDERAL DA 4 ${ }^{\mathrm{a}}$ REGIÃO. Apelação/Remessa Necessária n. 5001335-13.2012.4.04.7012. Relator Desembargador Federal Cândido Alfredo Silva Leal Júnior. Julgado em 23 de Junho de 2015. Disponibilizado no Diário Eletrônico em 25/06/2015. Disponível em: https://www.trf4.jus.br/trf4/controlador.php?acao=principal.

SUPREMO TRIBUNAL FEDERAL. Repercussão Geral no Recurso Extraordinário 1.017.365. Relator Ministro Edson Fachin. Disponibilizado no Diário Eletrônico em 11/04/2019. Disponível em: http://portal.stf.jus.br/processos/downloadPeca.asp?id=15339909193\&ext=.pdf

Ação Rescisória n. 2.756/PR. Relatora Ministra Cármen Lúcia. Medida Cautelar julgada em 4 de Setembro de 2019. Disponibilizado no Diário Eletrônico em 5/09/2019. Disponível em: http://portal.stf.jus.br/processos/detalhe.asp?incidente $=5756145$

CUNHA, Manuela Carneiro da. Índios no Brasil: história, direitos e cidadania. São Paulo: Claro Enigma, 2012.

DAN, Vivian Lara Caceres; ASSIS, Flavia Benedita Souza de. A tese do marco temporal nas decisões do Supremo Tribunal Federal e a controvérsia possessória acerca dos direitos territoriais indígenas. In: Teoria Jurídica Contemporânea, jul.-dez., p.264-286, 2020.

DUPRAT, Deborah. "O marco temporal de 5 de outubro de1988: TI Limão Verde", p.43-74. In: CUNHA, Manuela Carneiro da; BARBOSA, Samuel (Orgs.). Direitos dos povos indígenas em disputa. São Paulo: Editora UNESP, 2018.

ESCRIVÃO FILHO, Antônio; SOUSA JÚNIOR, José Geraldo de. Para um debate teóricoconceitual e político sobre os direitos humanos. Belo Horizonte: Editora D’Plácido, 2021.

FERNANDES, Ricardo Cid. Autoridade política Kaingang: um estudo sobre a construção da legitimidade política entre os Kaingang de Palmas/Paraná. Dissertação (Mestrado em Antropologia) - Programa de Pós-Graduação de Antropologia Social, Universidade Federal de Santa Catarina. Florianópolis, 1998.

OLIVEIRA, João Pacheco de. Uma etnologia dos "índios misturados"? Situação colonial, territorialização e fluxos culturais, MANA 4 (1),1998. p. 47-77.

"Sem a tutela, uma nova moldura de nação. O pós-constituição de 1988 e os povos indígenas", in BRASILIANA, vol.5, n.1 (nov.), 2016. p.200-229.

ROSEnVALD, Nelson; FARIAS, Cristiano Chaves de. Curso de Direito Civil: Direitos Reais. $9^{a}$ ed. Vol.5 Salvador: Editora JusPodivm, 2013.

SANTOS, Boaventura de Souza. Por uma concepção multicultural de direitos humanos. In: Revista Crítica de Ciências Sociais, n.48, p.11-32, jun.1997. 
STARCK, Gilberto; BRAGATO, Fernanda Frizzo. O impacto da tese do marco temporal nos processos judiciais que discutem direitos possessórios indígenas. In: Revista Direitos Sociais e Políticas Públicas, vol.8, n.1, p.245-282, 2020. Disponível em: https://fafibe.br/revista/index.php/direitos-sociais-politicas-pub/article/view/616/pdf Acesso em 15 jun 2021.

VESOLOSQUZKI KAINGANG, Marco; CASTRO, Ricardo Silveira. Armadilhas institucionais e retrocessos sociais para os povos indígenas no Brasil: como 1988 permitiu 2019? In: Políticas Indigenistas: contribuições para afirmação e defesa dos direitos indígenas [recurso eletrônico] / Rosa Maria Castilhos Fernandes [e] Angélica Domingos. Porto Alegre: Editora da UFRGS/CEGOV, 2020. 